\title{
Importance of Bacteriophage in Combating Hospital-Acquired Infection (HAI)
}

\author{
Ian Humphery-Smith \\ Skolkovo RusInnovations, Posledniy Pereulok, Moscow, Russia \\ Email: ianhs@skrirussia.com
}

Received 31 October 2014; revised 1 December 2014; accepted 23 December 2014

Copyright (c) 2014 by author and Scientific Research Publishing Inc. This work is licensed under the Creative Commons Attribution International License (CC BY). http://creativecommons.org/licenses/by/4.0/

\begin{abstract}
Bacteriophages have a potentially important role to play in reducing the global incidence of Hospital Acquired Infection (HAI). Their use should be focused on reducing the use and over-use of antibiotics as part of integrated control measures in conjunction with various vaccination, sanitation procedures and prophylactic and treatment regimens. Bacteriophages offer exquisite specificity and efficacy in killing target bacterial strains, a phenomenon known for almost 100 years. However, their efficacy with respect to broad-spectrum antibiotics is poor due to the highly strainselective nature of their killing and their rapid elimination from the body. Bacteriophage killing is a naturally-occurring process capable of limiting and eliminating bacterial populations in humans. This is achieved through exponential amplification of their number, if and when, they encounter a target bacterium. Unfortunately, processes employed for their commercial production today do not meet the same rigour as dictated for pharmaceutical products. Batch-to-batch reproducibility and molecular definition of target and phage strains must be demanded before their clinical use can become widespread. Elsewhere, historical data have demonstrated safety in humans beyond any doubt. Because patients continue to die in our healthcare centers internationally, the use of bacteriophage to help fight HAI should be reassessed. Here, relevant literature is reviewed.
\end{abstract}

\section{Keywords}

Nosocomial Infection, Hospital Acquired Infection, Bacteriophage, Multiple Drug Resistance

\section{Introduction}

The gambit of bacterial species that constitute the human microbiome is consistently complex and comprised of endemic and transient species and populations that are in a continuous state of dynamic flux. Multiple sites across the surface and within the human body provide innumerable habitats for numerous bacterial species that 
are formed into a local communal assemblage inhabiting a particular biotope. The latter are never monogenic in nature and are comprised of communities made-up of multiple species of cultivable and non-cultivable commensals, symbionts and pathogens. Individual species may evolve from harmless commensals into life-threatening pathogens through a chain of colonisation as a consequence of the reduced or increased diversity of bacterial communities and host factors, such as, age, sex, immune-competence and general state of health of the host organism. Thus, bacteria can be occasionally pathogenic or often pathogenic depending upon their site of multiplication in both a facultative and obligatory manner. In turn, all manner of healthcare interventions can disrupt day-to-day status quo and the interspecies balance within bacterial communities to produce infectious states that are detrimental and/or life threatening to the human host, i.e. as a function of an infectious organism's relative virulence and infectivity.

In a hospital setting, the infections that occur naturally in our bodies and those acquired in our healthcare facilities both contribute to life-threatening scenarios. The purpose of this literature review is to outline the overwhelming body of evidence that underwrites the proven efficacy and safety of bacteriophage for their eventual use in treating Hospital-Acquired Infection (HAI).

\section{Hospital-Acquired Infection (Nosocomial Disease)}

Since the discovery of penicillin and streptomycin and their widespread use internationally since the end of the Second World War, the world has become accustomed to the use of a wide variety of broad-spectrum antibiotics as a means to treat a multitude of bacterial infections affecting humankind. Due to their over- and uncontrolleduse, the efficacy of these antibiotics against target microbial infections has become less and less effective over time and this is producing an alarming situation associated with huge economic cost to patients and healthcare providers alike [1] [2]. Today, multiple drug-resistant bacteria are commonplace, particularly within our healthcare facilities. A "nosocomial infection" or so called "hospital-acquired infection" (HAI) can be defined as "An infection acquired in hospital by a patient who was admitted for a reason other than that infection. An infection occurring in a patient in a hospital or other health care facility in whom the infection was not present or incubating at the time of admission". This includes infections acquired in the hospital but appearing after discharge, and also occupational infections among staff of the healthcare facility [3].

Patient care is provided in facilities which range from highly-equipped clinics and technologically-advanced university hospitals to front-line units with only basic facilities. Despite progress in public health and hospital care, infections continue to develop in hospitalised patients. Many factors promote infection among hospitalised patients: decreased immunity among patients; the increasing variety of medical procedures and invasive techniques creating potential routes of invention; and the transmission of the drug-resistant bacteria among crowded hospital populations, where poor infection control practices can facilitate transmission. Infections acquired in a healthcare setting may take the form of acute or chronic infection.

Nosocomial infections occur worldwide and affect both rich and poor countries alike. Infections acquired in healthcare settings are among the major causes of death and increased morbidity among hospitalized patients. They are a significant burden both for the patient and public health authorities, not to mention the increasinglyimportant economic burden of extended hospital stay [3]. A prevalence survey conducted under the auspices of WHO in 55 hospitals of 14 countries representing 4 WHO Regions (Europe, Eastern Mediterranean, South-East Asia and Western Pacific) showed an average of $8.7 \%$ of hospital patients had nosocomial infections [3]. At any moment, more than 1.4 million people worldwide suffer from infectious complications acquired in hospital. This is due to a dwindling arsenal of effective antibiotics to combat these superbugs.

New approaches to antibiotic therapy and prevention are much needed for both human and animal infections, because broad-spectrum antibiotics have become significantly less effective over the last 70 years due to the development of resistance by bacterial species in our hospitals, in our communities and in agriculture. No situation better exemplifies this statement than the December 2012, US FDA approval for Compassionate Use of the compound Bedaquiline to help combat multiple drug-resistant tuberculosis (MDR-TB) and extensive multiple drug-resistant tuberculosis (X-MDR-TB). No new antibiotic had been brought to market over the last four decades; and this in the face of dwindling potency, more toxic, more costly and longer duration drug administration for a disease of global relevance.

Each year some 2.2 and 3.0 million individuals in respectively the USA and Europe acquire infections from a healthcare facility. Approximately $1 / 20$ to $1 / 16$ die as a result and the remainder suffer the consequences of in- 
creased morbidity and/or extended hospital stay of 3 - 19 days with an average of 7 - 9 days. The cost of extended hospital stay and litigation is a significant burden on already-stressed private and public healthcare systems. In developing countries, mortality rates are even higher, while X-MDR TB could take on epidemic proportions internationally, i.e. if not curtailed. Immuno-compromised individuals particularly susceptible and may act as a community-based reservoir that further serves to expand the infection base. The most recent data available from the European Centre for Disease Prevention and Control (2013) estimated some 4,100,000 healthcareassociated infections occur across the EU every year and of these approximately 37,000 die as a direct consequence.

The most frequent nosocomial infections are those of the urinary tract, all manner of post-operative wounds, pneumonia and bacteraemia. By far, the highest prevalence of nosocomial infections occurs in Intensive Care Units and in acute surgical, burns and orthopaedic wards. Infection rates are higher among patients with increased susceptibility due to old age, underlying disease and immunosuppression due to chemotherapy and/or disease [3].

Hospital-acquired infections add to functional disability and emotional stress of the patient and may, in some cases, lead to disabling conditions that reduce the quality of life. Coella et al. [4] showed that the overall increase in the duration of hospitalization for patients with surgical wound infections was 8.2 days, ranging from 3 days for gynaecology to 9.9 for general surgery and 19.8 for orthopaedic surgery. More recent findings are consistent with these indicative figures [2] [5]. Prolonged stay not only increases direct costs to patients or payers, but also indirect costs due to lost work. The increased use of drugs, the need for isolation, and the use of additional laboratory and other diagnostic studies also contribute to costs. Hospital-acquired infections add to the imbalance between resource allocation for primary and secondary health care by diverting scarce funds to the management of potentially preventable conditions. The more advancing age of patients admitted to health care settings, the greater prevalence of chronic diseases among admitted patients, and the increased use of diagnostic and therapeutic procedures, which in turn affect host defenses, will mostly likely increase exposure to nosocomial infections in the future.

It is also important to note that organisms causing nosocomial infections can be transmitted to the community through discharged patients, staff, and visitors. If organisms are multidrug resistant, they may also cause significant disease in the community.

\section{Bacteriophage}

The history of the discovery of bacteriophage and their subsequent use in combating bacterial infections has been comprehensively reviewed [6]-[18]. The initial discovery of bacteriophages is attributed to Frederick Twort in 1915 and Felix Herelle in 1917. Herelle went on to demonstrate the efficacy of these novel biological elements in fighting all manner of infection in several settings that heightened international awareness of their potential to successfully eradicate disease. Most notable of Herelle's exploits was the eradication of an epidemic of Avian Typhoid fever in France. He also studied cholera patients in India. In 1927 over the course of a few months, Herelle was able to reduce the death toll due to cholera from $60 \%$ to $8 \%$ by inoculating wells with bacteriophage isolated from cholera patients. The origin of the curative properties of the far-from-clean waters of the Ganges River, as sought out by the Hindu faithful, can possibly be attributed to the gradual build-up and abundance in the waters of the Ganges of bacteriophage directed against cholera, and particularly their curative powers against this deadly infection during cholera epidemics. In 1934, Herelle moved to Tbilisi in Georgia to renew acquaintances with Georges Eliava. Together they were responsible for bacteriophage being employed routinely to treat all manner of infections to the former Soviet Union. Outside the former Soviet Union, phages cocktails were to prove less reliable than broad spectrum antibiotics, i.e. once the latter became widely available after the Second World War; although during World War II, the Soviet Union used bacteriophages to treat many soldiers infected with various bacterial diseases, e.g. dysentery and gangrene.

From early-on, however, it became evident to Herelle and others that the use of phage cocktails was often unreliable. This was likely due to many factors. Most notable is the fact that the exact constituents, dosages and batch-to-batch consistency of the preparations employed to fight infections with bacteriophage have rarely, if ever, been subjected to the same rigour of production under Good Manufacturing Procedures, i.e. as are applied to antibiotics or pharmaceutical products sold internationally. Thus, variability in patient outcomes can be attributed in part to the inherent variable of what was actually given to patients. In addition, bacteriophages are 
inherently highly-specific to particular strains of bacteria. This limits their ability to target different strains of the same bacterial species beyond those for which they are specific. This specificity is a result of restricted receptor molecules expressed on the surface of the bacterial target. Therefore, preparations that are efficient at killing one strain of a bacterial species may have zero effect on another strain of the same species that is producing exactly the same clinical symptoms in patients. Indeed, the nature of phage specificity is such that it can be exploited as a diagnostic test for bacterial strains [19]-[23]. It is noteworthy, however, one bacteriophage may kill one strain of a particular target species and not another, however, over time bacteria may evolve to express resistance to a given bacteriophage strain.

The US pharmaceutical company Eli Lilly, attempted to commercialise bacteriophage during the 1940s, but this was short-lived and curtailed with the advent of antibiotics. Supporters of bacteriophage-based therapies have often attempted to garner support for their cause by stating that antibiotics are less desirable than bacteriophage because the former effectively kill both the deleterious and the beneficial bacterial flora simultaneously, while bacteriophage kill in a highly selective species and strain-specific manner.

\section{Bacteriophage and Human and Animal Safety}

It is noteworthy, that humans and other mammalian species have over evolutionary time learnt to fight disease using both non-specific defences and specific immune-modulated means. Non-host-engendered killing of bacteria by phage represents a significant adjunct to these defence mechanisms both in and on our bodies. Phage disseminate within the body remarkably well. If by chance, however, they encounter their target bacterial host, they possess the capacity to explode in number thereby limiting bacterial populations in situ, for both commensals and pathogens alike. Bacteriophages represent an ancient and naturally occurring biological process that has evolved to exploit the fruits of exponential bacterial growth.

Bacteriophages are defined, as their name would suggest, as "eaters of bacteria". They bind specific receptors found only on the surface of bacteria; and can therefore not directly infect mammalian or other eukaryotic cells. Bacteriophages are probably the most common "self-replicating entity" encountered on Earth, even more than their bacterial hosts. Estimates run to some $10^{31}$ particles [24]. Bacteriophages are found throughout our bodies and the surrounding environment and, as such, we eat them daily and play host to multitudes of different bacteriophages within our very own microbiomes in and on the human body.

A massive amount of scientific evidence has been gathered to demonstrate exactly how lytic bacteriophage reproduce and thereby kill bacteria. Several authors have detailed the history of the discovery of bacteriophage, their past use in fighting disease in humans and animals and the overall accumulation of our molecular knowledge that underwrites these processes [6]-[18]. Indeed, the ability of bacteriophage to kill bacteria and resolve human infection has been known since many years. In 1917, Hérelle reported the use of bacteriophage against bacterial dysentery (English translation after that detailed by Dublanchet [8]:

"The next morning, on opening the incubator, I experienced one of those rare moments of intense emotion... I saw that the broth culture, which the night before had been very turbid (due to the presence of high numbers of bacteria growing in the broth solution), was perfectly clear (due to the killing action of the bactiophage lytic effect on and associated rupture of the bacterial cell wall): all the bacteria had vanished, they had dissolved away like sugar in water. As for the agar spread, it was devoid of all (bacterial) growth... in a flash, I had understood: What caused my clear spots was in fact an invisible microbe, a filterable virus, but a virus parasitic on bacteria... If this is true, the same thing has probably occurred during the night in the sick man... He should now be cured. In fact, during the night, his general condition had greatly improved and convalescence was beginning."

This and subsequent results from Hérelle, and others since, have always held out great hope that bacteriophage could be employed to cure infections due to all manner of bacteria. In the early 1970s, scientists in the USA and the US government realized that they had been inoculating humans with untold trillions of bacteriophages contained in live vaccines doses and this for many different vaccines administered to millions of the US population and individuals around the world. Without doubt, the many millions of doses of phage-containing vaccines administered internationally constitute collectively a wonderful Linus-Pauling-style ("Mega- Study”) conducted to date as concerns the overall safety of bacteriophages in humans.

The following historical data concerning the safety attributes of bacteriophage combine to demonstrate antic- 
ipated safety for their therapeutic use to treat infections in humans:

1) As the most abundant life-form on the planet earth, bacteriophages are by default probably present and active in and against most, if not all, species constituting the human microbiome. Where bacteria are present, one will also encounter bacteriophages. Thus, on a daily basis, humans either in our food and drink or on our skin or in our body orifices co-exist in the presence of billions and billions of bacteriophages. The latter recognize their bacterial host by surface receptors found uniquely on the surface of a specific strain of their bacterial host organism. They are not known to be capable of directly infecting mammalian cells. Bacteriophages have undergone co-evolution with their bacterial hosts so as to recognize and infect target bacterial cells with an extraordinary level of specificity and affinity of binding [25]. They also manifest remarkably low susceptibility to variations in temperature and $\mathrm{pH}$, organic solvents and proteases, a capacity that is equally coupled with an ability to recognize the difference between living and dead cells [25]. Human beings as exposed daily to a deluge of bacteriophages. Many of these are destroyed by gastric juices when ingested orally, but many also make it across the intestinal wall and into the blood stream and even across the blood brain barrier. Elsewhere, bacteriophages have been demonstrated to harmlessly make their way to brain tissue of mice via the olfactory neuron route following intra-nasal inoculation and efficiently penetrating biological membranes in so doing [26]. This vindicates the earlier seminal work of Dubos [18] [27], who was able to clearly demonstrate the passage of bacteriophage across the blood brain barrier to fight bacterial infection. To date, the presence of bacteriophage in our bodies is not known to cause detriment. Indeed, bacteriophages are actually beneficial by assisting the body to fight-off infectious agents and limit the damage they provoke.

2) Trillions of bacteriophages have been administered to millions of people as part of live organism vaccines around the globe [28] [29]. In 1975, the realization that numerous human vaccines were contaminated with bacteriophage resulted in a high-profile exemption being issued by the US Food and Drug Administration (FDA). This effectively meant that FDA was to formally approve the inclusion of bacteriophages of various and unknown kinds in human vaccines. Some years later, this resulted in FDA's tolerance of vaccine contaminants in a court case in 1987, that stated:

a) "Each seed virus used in manufacture shall be demonstrated to be free of extraneous microbial agents except for unavoidable bacteriophage."

b) In February, 1975 Gina Bari Kolata [30], wrote an article entitled "Phage in Live Virus Vaccines: Are They Harmful to People?" Gina Bari Kolata wrote: In 1973, scientists at the Bureau of Biologics of the Food and Drug Administration (FDA) reported that all live virus vaccines are grossly contaminated with phage (viruses that infect bacteria)... This finding presented a problem since federal regulations forbade extraneous material in vaccines and no one knew whether phage are harmful to human beings or whether they could be removed from vaccines. The temporary solution was to amend the regulations so as to permit phage in vaccines [30].

3) As a direct consequence of these findings, namely, that bacteriophages were heavily contaminating human vaccines, the US FDA set about proving that bacteriophages as isolated from therapeutic vaccines were unlikely to cause harm to humans [31].

4) Multiple animals studies directed at treating bacteraemia with bacteriophage have been able to demonstrate the absence of an immune response in animals subjected to phage alone, i.e. as part of a placebo control studies in the absence of experimental infection [32]-[38]. The explanation of such results is probably linked to the extremely rapid clearing of bacteriophage from the blood by the body's reticulo-endothelial system [39]. Indeed, Inchley was able to demonstrate using radio-labelled T4 phage that the mouse liver phagocytized more than $99 \%$ of circulating phage within 30 minutes [40]. The conclusion must be that they do not persist long within the body.

5) Elsewhere, several authors have attempted to collect published accounts of the many thousands of human patients administered bacteriophage and effectively treated in the former Soviet Union [7] [9] [10] [17] [18]. In addition, one should note that of recent times the Russian state-owned corporation, MicroGen, continues to sell millions of doses per annum of bacteriophage destined for human use. In 2013, MicroGen sold an estimate 26 million doses and this without widespread reports of detectable deleterious side-effects or a hecatomb in the Russian population.

6) Endotoxins and immunogens are sometimes cited as a potential cause for concern within preparations of bacteriophage destined for administration to humans. Today, there exist effective methods for the removal of these contaminants, for example, EndoTrap ${ }^{\circledR}$ Blue high endotoxin affinity ligand (Manufactured by Hyglos $\mathrm{GmbH}$, Germany) which is a proteinaceous matrix derived from a bacteriophage that is covalently immobilized 
on agarose beads [41]. It is equally important to note that during sepsis and associated bacteraemia, bacterial infections will be producing far more such contaminants within the body. By doing away with the cause of sepsis and unwanted endotoxin and immunogen production, the body can be allowed to rapidly return to health. Indeed several authors throughout history have remarked upon the dramatically rapid return to a healthy state following administration of bacteriophage. None better exemplifies this than original observations of d'Herelle, as cited above [8], accounts of several other miraculously rapid recoveries [10] and that of Knouf et al. [42] reporting on the treatment of typhoid patients in California prior to the availability of the antibiotic chloramphenicol "In 24 26 hours, patients that had been comatose and in the 'typhoid state' amazed everyone by their cheerful, grateful attitude".

\section{A Dedicated Regulatory Framework for the Clinical Use of Bacteriophage}

In the area of bacteriophage-based therapy, there exists a need for greater stringency and control in the manner in which bacteriophage are currently prepared for commercial sale [17] [41] [43]-[47]. This is essential if such treatments are to receive regulatory approval in various jurisdictions and be linked to improved batch-to-batch reproducibility as it applies to content and efficacy.

As for pharmaceutical preparation and vaccines in most developed countries around the world, such measures include the need for bacteriophage strains should be better characterized molecularly in advance of clinical use, namely:

- Triple cloning/passage of both bacteriophage and accompanying confirmed target bacterial strain.

- Molecular typing by PCR or RT-PCR; MALDI-TOF mass spectrometry, nucleic acid fingerprinting; or total or partial nucleic acid sequencing of the bacteriophage strain; and similarly for the confirmed bacterial strain lysed by a lytic phage strain; i.e. molecular typing of the specific host and parasite combination.

- Demonstration of an absence of temperate or lysogenic bacteriophage.

- Proof of "batch-to-batch" molecular consistency of the bacteriophage preparations; and this in addition to the maintenance of a given bacteriophage strain's ability to kill its target bacterial strain over time as determined by regular repeat testing.

○ Production of a detailed Batch File Record compliant with 21CRFpart11 data retention guidelines

- Although bacteriophage may kill their target species most effectively, sterility testing of phage containing preparations is essential to verify the absence of non-target and/or viable bacteria containing lysogenic species. These contaminating bacterial species may in turn provoke disease, i.e. if included in preparations destined for treating disease.

- A battery of pre-clinical and clinical testing designed to define both the safety and efficacy of a specific bacteriophage preparation. Such measures should routinely include:

○ Pharmacokinetics, toxicity and immunogenicity testing, ideally following the elimination or reduction of endo- and exo-toxins levels (derived from lysed bacterial cells) from bacteriophage preparations [31]

- Shelf-life stability at $4^{\circ} \mathrm{C}$

$\circ \mathrm{pH}$ control

- Absence of pyrogenicityand cytotoxicity

- Transmission electron microscopy to confirm the presence of the expected morphology of virion particles

- And finally, Certification of the Batch File record by an industrial pharmacist.

The abovementioned body of evidence can then be submitted for approval by regulatory authorities, i.e. for their use as treatments destined to be administered to humans more in line with other therapeutic substances. Traditionally, this has been far from the case. It is, therefore, high time that these therapeutic preparations are brought into the modern era and commercial enterprises purveying bacteriophage as therapeutic substances are obliged to conform to greater regulatory rigour. That said, bacteriophage probably warrant special procedures for regulatory approval. These should take into account the fact that bacteriophages do kill their hosts, namely, proof of efficacy is able to be transferred from an in vitro setting to an in vivo context; and secondly, the masses of historical data relating to the safety of naturally-occurring co-habitants of the human body and our own microbiome.

In this manner, phage-based therapies could more readily enter into the modern world of molecularly-defined constituents, preclinical safety and efficacy testing and clinical trials prior to generalize release. Furthermore, annual Influenza epidemics and the emergence of SARS Virus, for example, should have helped instruct regulatory bodies of the need for rapid and more flexible responses to emerging and life-threatening pandemics in 
order to prevent major losses of life. Many of these emerging diseases pose threats not dissimilar to the situation we face every day in our healthcare facilities globally.

\section{Conclusions}

Infection Control Units within healthcare facilities in both developed and developing countries must continue to play a critical role, i.e. if deaths due to HAI are to be eliminated. This involves identification of bacterial strains producing life-threatening disease, many of which have become Multiple Drug Resistant; and orchestration of the deployment of appropriate treatments and prophylactic measures designed to limit infection across a given healthcare facility. These efforts should include the use of appropriate phage strains designed to kill relevant bacterial strains responsible for causing deaths and/or complications and extended hospitals stays.

At great cost, patients are failing to be protected adequately from the global scourge of HAI. This is the tenth largest cause of death reported in US hospitals and is currently far more dangerous and widespread than emerging health threats, such as, Ebola Virus. The question that healthcare administrators and the public-at-large must ask is: "If members of my immediate family were dying in an Intensive Care Unit due to 'post-operative complications', namely, generalized sepsis due to a Multiple Drug Resistant strain of HAI, would I wish the treating clinicians to save the patient's life with known and proven treatments?" Or, merely standby and state that: "I am terribly sorry but there was nothing more we could do to save the life of your loved-one", i.e. once the repertoire of available antibiotics have been exhausted by the treating clinician. The latter scenario is being played out repeatedly around the world. Yet, still today bacteriophages are not authorized for use in fighting HAI in Western medicine. Appropriate national authorization of bacteriophage to be employed initially for "Compassionate Use" is long overdue in order to avoid preventable deaths in our healthcare facilities, i.e. as an initial first-step towards more widespread acceptance of these known remedies in the fight against life-threatening disease.

It may be surprising to many to learn that still today within the Russian Federation, an estimated 26.5 million doses of bacteriophage are sold annually by the leading producer, MicroGen. This occurs without inducing a hecatomb in the Russian population and helps successfully to keep at bay a multitude of infectious agents.

Numerous authors [41] [43]-[47] have called for a change in the manner in which bacteriophages are produced and sold; and, more importantly still, in the rules governing their registration for clinical use. Elsewhere and faced with the threat of SARS, new influenza strains and exotic diseases that have yet to kill many, public health regulators in many countries appear to be able to respond rapidly to the best of their ability to emerging threats. However, faced with the all-too-common deaths in our healthcare facilities, current recommended protocols, even in our best healthcare facilities, are failing to significantly reduce the incidence of HAI. This is a major problem of global importance, whereby HAI is responsible for significant mortality, morbidity and cost to patients and both public and private healthcare providers and payers. Urgently, this situation needs to be changed.

Bacteriophage can assist in this respect, particularly as part of integrated infection prevention and control measures. In turn, the latter can help restrict the level of use of antibiotics in our healthcare centers and thereby allow more effective use of our available antibiotic arsenal, i.e. when other measures fail. Here, the first and paramount objective must be to reduce the overall incidence of HAI.

Importantly, it should be noted that no "magic bullets" exist when it comes to fighting HAI. However, more widespread use of phage is increasingly becoming our only and last alternative. Nonetheless, such measures should be introduced as part of concerted efforts to reduce the overall incidence of HAI and treat life-threatening infections caused by Multiple Drug Resistant bacteria, particularly as the number of antibiotics remaining to fight these infections is now seriously depleted.

Proponents of bacteriophage have often been overly simplistic in citing their ability to do away with the problem. The challenge posed by HAI is far more complex and without fail demands a multipronged attack. However, conducting this battle without employing nature's best, safest and most effective tool for killing bacteria borders on criminal negligence and healthcare authorities internationally should increasingly be held responsible for not including bacteriophage in their armoury to fight the devastation provoked by HAI worldwide. Bacteriophages do work and we do have alternatives methods today in addition to antibiotics. Unfortunately, these proven tools for combating bacterial disease are not being deployed.

\section{References}

[1] WHO (2014) Antimicrobical Resistance: Global Report on Surveillance. World Health Organization, Geneva, 1-257. 
[2] (2013) Antibiotic Resistance Threats in the USA. U.S. Department of Health and Human Services Centers for Disease Control and Prevention, Atlanta, 1-114.

[3] Ducel, G., Fabry, J. and Nicolle, L. (2002) Prevention of Hospital-Acquired Infections: A Practical Guide. World Health Organization, Geneva, 1-64.

[4] Coella, R., Glenister, H., Fereres, J., Bartlett, C., Leigh, D., Sedgwick, J. and Cooke, E.M. (1993) The Cost of Infection in Surgical Patients: A Case-Control Study. Journal of Hospital Infection, 25, 239-250. http://dx.doi.org/10.1016/0195-6701(93)90110-L

[5] Rosenthal, V.D., Maki, D.G., Mehta, Y., Apisarnthanarak, A., Fisher, D., Medeiros, E.A., et al. (2012) International Nosocomial Infection Control Consortium (INICC) Report, Data Summary of 36 Countries, for 2004-2009. American Journal of Infection Control, 40, 396-407. http://dx.doi.org/10.1016/j.ajic.2011.05.020

[6] Lu, T.K. and Koeris, M.S. (2011) The Next Generation of Bacteriophage Therapy. Current Opinion in Microbiology, 14, 524-531. http://dx.doi.org/10.1016/j.mib.2011.07.028

[7] Keen, E.C. (2012) Phage Therapy: Concept to Cure. Frontiers in Microbiology, 3, 1-3. http://dx.doi.org/10.3389/fmicb.2012.00238

[8] Dublanchet, A. and Bourne, S. (2007) The Epic of Phage Therapy. Canadian Journal of Infectious Disease and Medical Microbiology, 18, 15-18.

[9] Kutter, E., De Vos, D., Gvasalia, G., Alavidze, Z., Gogokhia, L., Kuhl, S. and Abendon, S.T. (2010) Phage Therapy in Clinical Practice: Treatment of Human Infections. Current Pharmaceutical Biotechnology, 11, 69-86. http://dx.doi.org/10.2174/138920110790725401

[10] Abedon, S.T., Kuhl, S.J., Blasdel, B.G. and Kutter, E.M. (2011) Phage Treatment of Human Infections. Bacteriophage, 1, 66-85. http://dx.doi.org/10.4161/bact.1.2.15845

[11] Chanishvili, N. (2012) A Literature Review of the Practical Application of Bacteriophage Research. Nova Science Publishers, Hauppauge.

[12] Wittebole, X., Roock, S.D. and Opal, S.M. (2014) A Historical Overview of Bacteriophage Therapy as an Alternative to Antibiotics for the Treatment of Bacterial Pathogens. Virulence, 5, 226-235. http://dx.doi.org/10.4161/viru.25991

[13] Chan, K.B., Abedon, S.T. and Loc-Carrillo, C. (2013) Phage Cocktails and the Future of Phage Therapy. Future Microbiology, 8, 769-783. http://dx.doi.org/10.2217/fmb.13.47

[14] Merril, C.R., Scholl, D. and Adhya, S.L. (2003) The Prospect for Bactreriopharge Therapy in Western Medicine. Nature Reviews in Drug Discovery, 2, 489-497. http://dx.doi.org/10.1038/nrd1111

[15] Fruciano, D.E. and Bourne, S. (2007) Phage as an Antimicrobial Agent: D’Herelle’s Heretical Theories and Their Role in the Decline of Phage Prophylaxis in the West. Canadian Journal of Infectious Disease and Medical Microbiology, 18, 19-26.

[16] Harper, D.R., Anderson, J. and Enright, M.C. (2011) Phage Therapy: Delivering on the Promise. Therapeutic Delivery, 2, 935-947. http://dx.doi.org/10.4155/tde.11.64

[17] Borysowski, J. (2014) Phage Therapy: Current Research and Applications. Caister Academic Press, Norfolk.

[18] Atterbury, R.J. (2009) Bacteriophage Biocontrol in Animals and Meat Products. Microbial Biotechnology, 2, 601-612. http://dx.doi.org/10.1111/j.1751-7915.2009.00089.x

[19] Traore, H. (2007) Low-Cost Rapid Detection of Rifampicin Resistant Tuberculosis Using Bacteriophage in Kampula, Uganda. Annals of Clinical Microbiology and Antimicrobials, 6, 1-6. http://dx.doi.org/10.1186/1476-0711-6-1

[20] Pai, M. and Kalantri, S.P. (2005) Bacteriophage-Based Tests for Tuberculosis. Indian Journal of Medical Microbiology, 23, 149-150. http://dx.doi.org/10.4103/0255-0857.16584

[21] Albert, H., Trollip, A.P., Mole, R.J., Hatch, S.J. and Blumberg, L. (2002) Rapid Indication of Multidrug-Resistant Tuberculosis from Liquid Cultures Using FAST Plaque TB-RIF, a Manual Phage-Based Test. International Journal of Tuberculosis and Lung Disease, 6, 523-528.

[22] Albert, H., Trollip, A., Seaman, T. and Mole, R.J. (2004) Simple, Phage-Based (FAST Plaque) Technology to Determine Rifampicin Resistance of Mycobacterium tuberculosis Directly from Sputum. International Journal of Tuberculosis and Lung Disease, 8, 1114-1119.

[23] Jain, P., Thaler, D.S., Maiga, M., Timmins, G.S., Bishai, W.R., Hatfull, G.F., Larsen, M.H. and Jacobs, W.R. (2011) Reporter Phage and Breath Tests: Emerging Phenotypic Assays for Diagnosing Active Tuberculosis, Antibiotic Resistance, and Treatment Efficacy. Journal of Infectious Disease, 204, 142-150. http://dx.doi.org/10.1093/infdis/jir454

[24] Schmelcher, M. and Loessner, M.J. (2014) Application of Bacteriophages for Detection of Foodborne Pathogens. Bacteriophage, 4, e28137.

[25] Hendrix, R.W. (1999) Evolutionary Relationships among Diverse Bacteriophages and Prophages—All the World's a 
Phage. Proceedings of the National Academy of Sciences of the United States of America, 96, 2192-2197. http://dx.doi.org/10.1073/pnas.96.5.2192

[26] Frenkel, D. and Solomon, B. (2001) Filamentous Phage as Vector-Mediated Antibody Delivery to the Brain. Proceedings of the National Academy of Sciences of the United States of America, 99, 5675-5679. http://dx.doi.org/10.1073/pnas.072027199

[27] Dubos, R.J., Straus, J.H. and Pierce, C. (1943) The Multiplication of Bacteriophage in Vivo and Its Protective Effect against an Experimental Infection with Shigella dysenteriae. Journal of Experimental Medicine, 78, 161-168. http://dx.doi.org/10.1084/jem.78.3.161

[28] Merril, C.R., Friedman, T.B., Attallah, A.F., Geier, M.R., Krell, K. and Yarkin, R. (1972) Isolation of Bacteriophages from Commercial Sera. In Vitro, 8, 91-93. http://dx.doi.org/10.1007/BF02615965

[29] Merril, C.R. (1975) Phage in Human Vaccines. Science Magazine, 188, 8. http://dx.doi.org/10.1126/science.188.4183.8

[30] Kolata, G.B. (1975) Phage in Live Virus Vaccines: Are They Harmful to People? Science Magazine, 187, 522-523. http://dx.doi.org/10.1126/science.187.4176.522

[31] Milstien, B.J., Walker, J.R. and Petricciane, J.C. (1977) Bacteriophages in Live Virus Vaccines: Lack of Evidence for Effects on the Genome of Rhesus Monkeys. Science Magazine, 197, 469-470. http://dx.doi.org/10.1126/science.406673

[32] Hung, C.H., Kuo, C.F., Wang, C.H., Wu, C.M. and Tsao, N. (2011) Experimental Phage Therapy in Treating Klebsiella pneumoniae-Mediated Liver Abscesses and Bacteremia in Mice. Antimicrobial Agents and Chemotherapy, 55, 13581365. http://dx.doi.org/10.1128/AAC.01123-10

[33] Biswas, B., Adhya, S., Washart, P., Paul, B., Trostel, A.N., Powell, B., Carlton, R. and Merril, C.R. (2002) Bacteriophage Therapy Rescues Mice Bacteremic from a Clinical Isolate of Vancomycin-Resistant Enterococcus faecium. Infection and Immunology, 70, 204-210. http://dx.doi.org/10.1128/IAI.70.1.204-210.2002

[34] Gupta, R. and Prasad, Y. (2011) Efficacy of Polyvalent Bacteriophage P-27/HP to Control Multidrug Resistant Staphylococcus aureus Associated with Human Infections. Current Microbiology, 62, 255-260. http://dx.doi.org/10.1007/s00284-010-9699-x

[35] Wang, J., Hu, B., Xu, M., Yan, Q., Lui, S., Zhu, X., Sun, Z., Tao, D., Ding, L., Reed, E., Gong, J., Li, Q. and Hu, J. (2005) Therapeutic Effectiveness of Bacteriophages in the Rescue of Mice with Extended Spectrum $\beta$-LactamaseProducing Escherichia coli Bacteremia. International Journal of Molecular Medicine, 17, 347-355.

[36] Wagenaar, J.A., Van Bergen, M.A.P., Mueller, M.A., Wassenaar, T.M. and Carlton, R.M. (2005) Phage Therapy Reduces Campylobacter jejuni Colonization in Broilers. Veterinary Microbiology, 109, 275-283. http://dx.doi.org/10.1016/j.vetmic.2005.06.002

[37] Sunagar, R., Patil, S.A. and Chandrakanth, R.K. (2010) Bacteriophage Therapy for Staphylococcus aureus Bacteremia in Streptozotocin-Induced Diabetic Mice. Research in Microbiology, 161, 854-860. http://dx.doi.org/10.1016/j.resmic.2010.09.011

[38] Barrow, P., Lovell, M. and Berchieri Jr., A. (1998) Use of Lytic Bacteriophage for Control of Experimental Escherichia coli Septicemia and Meningitis in Chickens and Calves. Clinical and Diagnostic Laboratory Immunology, 5, $294-$ 298.

[39] Merril, C., Biswas, B., Carlton, R.C., Jensen, N., Greed, G.J., Zullo, S. and Adhya, S. (1996) Long-Circulating Bacteriophage as Antibacterial Agents. Proceedings of the National Academy of Sciences, 93, 3188-3192. http://dx.doi.org/10.1073/pnas.93.8.3188

[40] Inchley, C.J. (1969) Activity of Mouse Kupffer Cells Following Intravenous Injection of T4 Bacteriophage. Clinical and Experimental Immunology, 5, 173-187.

[41] Merabishvili, M., Pirnay, J.P., Verbeken, G., Chanishvili, N., Tediashvili, M., Lashkhi, N., Glonti, T., Krylov, V., Mast, J., Parys, L.V., Lavigne, R., Volckaert, G., Mattheus, W., Verween, G., De Corte, P., Rose, T., Jennes, S., Zizi, M., De Vos, D. and Vaneechoutte, M. (2009) Quality-Controlled Small-Scale Production of a Well-Defined Bacteriophage Cocktail for Use in Human Clinical Trials. PLOS ONE, 4, e4944.

[42] Knouf, E.G., Ward, W.E., Reichle, P.A., Bower, A.G. and Hamilton, P.M. (1946) Treatment of Typhoid Fever with Type Specific Bacteriophage. Journal of the American Medical Association, 132, 134-138. http://dx.doi.org/10.1001/jama.1946.02870380016006

[43] Verbeken, G., Pirnay, J.P., Lavigne, R., Jennes, S., De Vos, D., Casteels, M. and Huys, I. (2014) Call for a Dedicated European Legal Framework for Bacteriophage Therapy. Archivum Immunologiae et Therapiae Experimentalis, 62, 117-129. http://dx.doi.org/10.1007/s00005-014-0269-y

[44] Pimay, J.P., De Vos, D., Verbeken, G., Merabishvili, M., Chanishvili, N., Vaneechoutte, M., Zizi, M., Laire, G., Lavigne, R., Huys, I., Van den Mooter, G., Buckling, A., Dabarbieux, L., Pouillot, F., Azeredo, J., Kutter, E., Dublanchet, 
A., Gorski, A. and Adamia, R. (2011) The Phage Therapy Paradigm: Prêt-à-Porter or Sur-mesure? Pharmaceutical Research, 28, 934-937. http://dx.doi.org/10.1007/s11095-010-0313-5

[45] Parracho, H., Burrowes, B., Enright, M., McConville, V. and Harper, D. (2012) The Role of Regulated Clinical Trials in the Development of Bacteriophage Therapeutics. Journal of Molecular and Genetic Medicine, 6, 279-286. http://dx.doi.org/10.4172/1747-0862.1000050

[46] Verbeken, G., Pirnay, J.P., De Vos, D., Jennes, S., Lavigne, R., Casteels, M. and Huys, I. (2012) Optimizing the European Regulatory Framework for Sustainable Bacteriophage Therapy in Human Medicine. Archivum Immunologiae et Therapiae Experimentalis, 60, 161-172. http://dx.doi.org/10.1007/s00005-012-0175-0

[47] Huys, I., Pirnay, J.P., Lavigne, R., Jennes, S., De Vos, D., Casteels, M. and Verbeken, G. (2013) Paving a Regulatory Pathway for Phage Therapy. EMBO Reports, 14, 947-1022. http://dx.doi.org/10.1038/embor.2013.163 
Scientific Research Publishing (SCIRP) is one of the largest Open Access journal publishers. It is currently publishing more than 200 open access, online, peer-reviewed journals covering a wide range of academic disciplines. SCIRP serves the worldwide academic communities and contributes to the progress and application of science with its publication.

Other selected journals from SCIRP are listed as below. Submit your manuscript to us via either submit@scirp.org or Online Submission Portal.
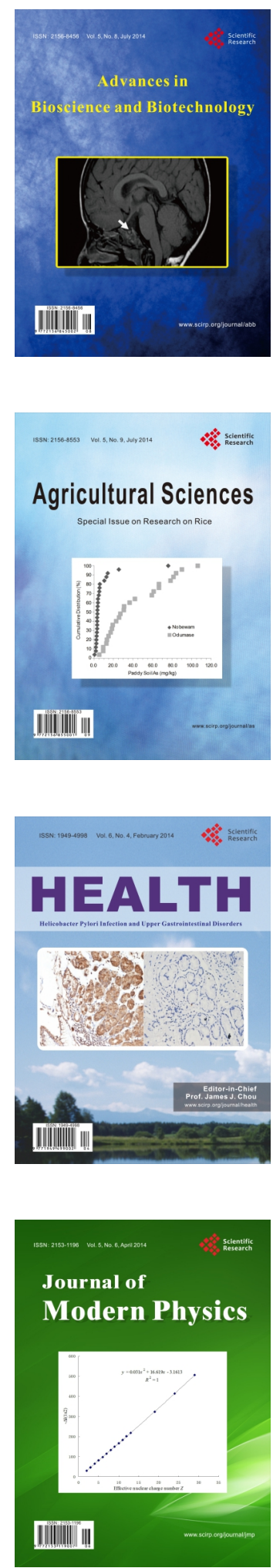
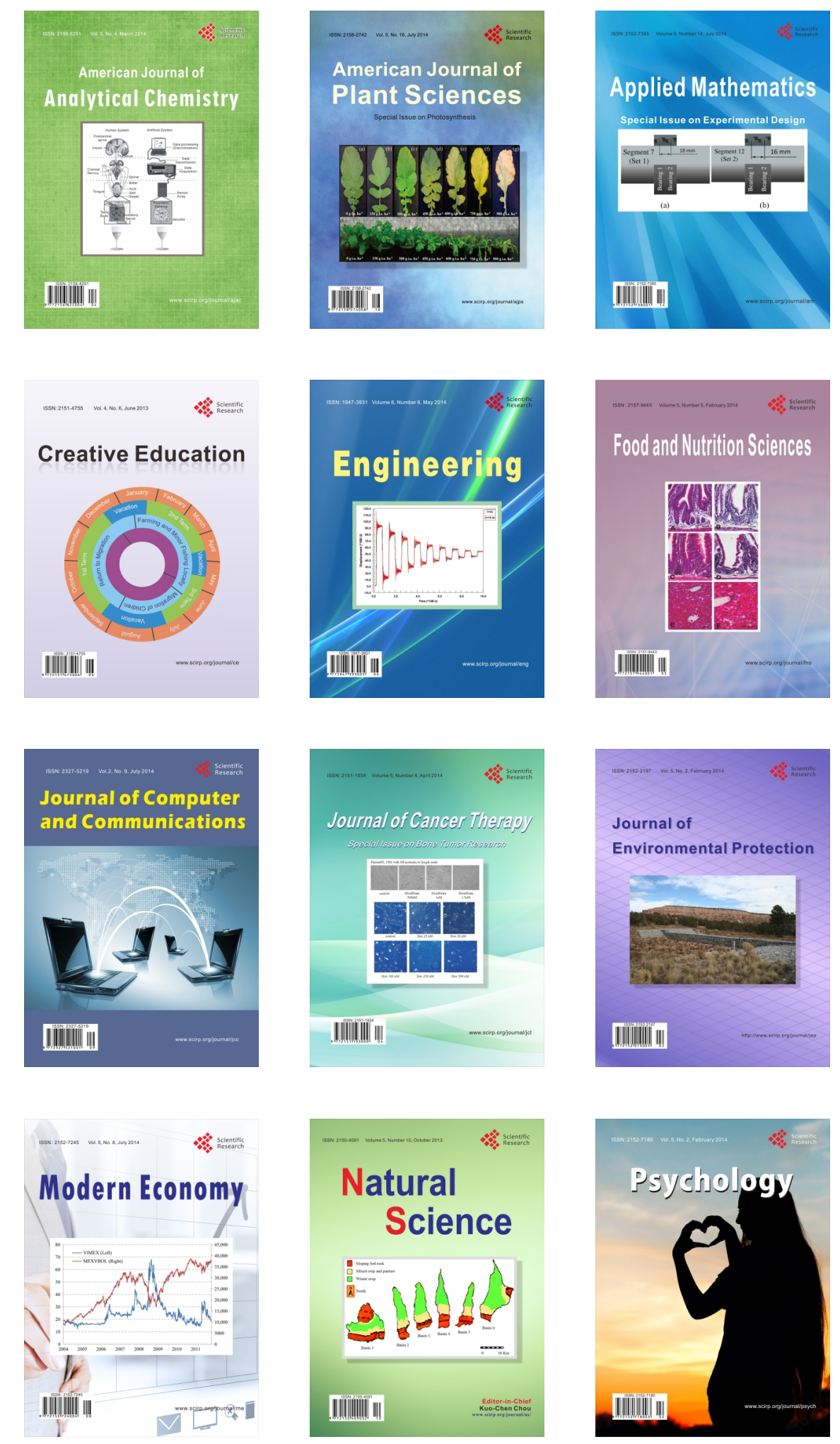